\title{
Using Rock Mechanics Concepts in Tectonic settings
}

\author{
Rwo Kersten* \\ Rock Mechanics Consultant, Wits University, South Africa
}

Submitted: December 3, 2019; Published: March 16, 2020

*Corresponding author: Rwo Kersten, Rock Mechanics Consultant, Wits University, South Africa

\section{Abstract}

Faulting, folding and subduction zones are the result of forces exceeding the strength of the rock in the earth crust and mantle, hence, if the yield/failure limits can be determined, the maximum value of the acting force is established. The rock strength for various temperatures and stress ratios is defined by the Mohr envelope and accepting that the vertical stress component can either be the minimum or the maximum principal stress, the limits of the maximum or minimum principal stress can be determined. By combining these values with the temperature gradients, thermal models and density variations the yield envelopes are determined and illustrated for a base case, a thermal, collision and subduction model. For verification of the results obtained the yield envelopes are transposed onto pressure temperature values of known metamorphic facies diagrams as well as a comparison between predicted and actual seismicity in subduction zones.

Keywords: Rock mechanics; Tectonic settings; Subduction zones; Temperature; Collision; Metamorphic facies; Actual seismicity; Shear stresses; Absolute quantity; Resistance

\section{Introduction}

Faulting, folding and subduction zones are the result of forces exceeding the strength of the rock in the earth's crust and mantle hence, if the yield/failure limits are determined, the maximum value of the acting force is defined. By including the load line of the system, it is also possible to predict possible stress drops for seismic areas. The yield limit of a rock mass is a function of a number of factors which need to be considered which are:

i. Rock strength, three-dimensional, at a range of expected temperatures.

ii. Load line of the system.

iii. Rate of change of the vertical stress component with depth.

iv. The temperature gradient and the rate of change with depth.

v. Density of the rock mass and its change with depth.

vi. The Poisson's ratio and its change with temperature.

Individually these quantities and functional relationships have been established from measurements and empirical relationships. The common parameter is the temperature and if a functional relationship can be established between the listed components with temperature it is possible to calculate the required yield values for a range of rock types and depths below surface. This article maps out a methodology that uses the above concepts to determine the yield limits for any rock type for a variety of temperature gradients. The individual functional relationships are based on realistic constants, but it is not assumed that these are the same for each and every case; they can be modified and improved upon as more information becomes available and refinement of the methodology. The yield limits or rock strengths in a two or three- dimensional stress field for various temperatures can be represented by the Mohr envelope which is defined by the principal and shear stresses. The slope of the envelope differs for various temperatures, generally flattening as it increases.

The vertical stress component in the earth crust is a function of the density of the rock mass times the depth and is for the present discussion considered an absolute quantity. The inter-relationship of the remainder of the variables listed have been established empirically. The discussion commences with establishing the relationship between the depth-temperature gradient and the vertical stress component and is fundamental to the methodology. The methodology further combines the remaining variables to calculate the yield limits as detailed in the first section. To 
illustrate the use of the methodology a series of examples are discussed generally of interest in tectonic history.

$\begin{array}{cl}\text { i. } & \text { Base case model } \\ \text { ii. } & \text { High temperature gradient } \\ \text { iii. } & \text { Collision zones } \\ \text { iv. } & \text { Subduction zones }\end{array}$

For each example the sustainable maximum force, or yield limit, is given over a relevant depth range and to test the veracity, the findings are plotted on existing metamorphic facies pressuretemperature diagrams and in the case of the subduction zone, seismic activity is incorporated. The term force/pressure used in the literature is insufficient to describe the state of stress in a continuum and the concept of principal and shear stresses have to be included. The definition of a principal stress is the orientation where the shear stress is zero. The principal stresses are further defined as maximum, intermediate and minimum in three dimensions. A knowledge of the principal stresses is sufficient to determine the yield limits.

\section{Definition of Failure and Yield}

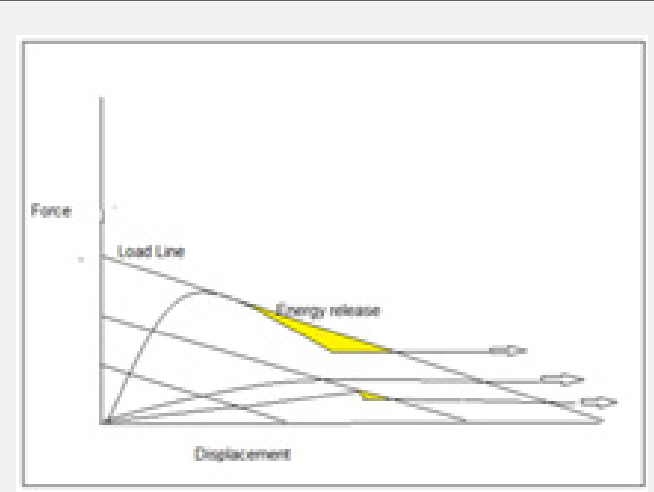

Figure 1: Schematic load lines with force displacement curves for brittle, plastic and stick slip response

A reduction in resistance after peak strength has been reached is termed brittle behaviour while for plastic response the plastic yield strength is maintained with increase in displacement. Yield in terms of the stress only does not describe the full process since the load line of the system has to be included, Kersten [1]. Figure 1 depicts the concept of brittle, plastic and stick slip mechanisms in terms of yield strength and the load line of the system. With increase in the acting forces, the load line progresses until the yield point is reached. For a brittle material, top curve in Figure 1, the displacement will follow the yield curve of the brittle material along which it will continue. The reduction in stress is a direct measure of the seismic stress drop and, in the process, energy is released, the amount dependent on the negative slope and extent of the material and the slope of the load line. For a plastic material, when the yield point has been reached, it will follow the yield line of the material. (Middle curve). Stick-slip occurs when there is strain hardening due to geometrical or temperature changes increasing the plastic yield limit until "brittle' yield occurs, releasing energy in the process, bottom curve.

\section{Defining the Tectonic Yield Envelope}

The Mohr envelope is defined by:

$$
\hat{\mathrm{o}}=\mathrm{c}+\text { Tanö }
$$

Where $\tau=$ Shear stress; $c=$ Cohesion; $\varphi=$ Angle of Mohr envelope. Figure 2 is a diagrammatic example of two Mohr envelopes for temperatures $T_{1}$ and $T_{2}$ for the same rock type. Note that the intercept ignores the cohesion value as it is insignificant compared to the stress values encountered in the earth crust. The envelope is fully defined by the minimum $\left(\sigma_{3}\right)$ and the maximum $\left(\sigma_{1}\right)$ principal stress while the shear stress is defined by the equation. Knowing the slope of the envelope and one of the principal stresses two alternative Mohr circles can be constructed; if the known value is the minimum then the alternative must be the maximum principal stress $\left(\sigma_{1}\right)$ and is determined by increasing the Mohr circle until it touches the envelope. The converse is true for if the known stress is the maximum, the minimum principal stress $\left(\sigma_{3}\right)$ is obtained by constructing the Mohr circle to the left there of (Figure 2). For any known vertical stress component either of the two options can be calculated and the ratio between them established. For instance, for the vertical stress of $120 \mathrm{MPa}$, the minimum principal stress is $50 \mathrm{MPa}$, a ratio of $50 / 120$. For the alternate the maximum principal stress is $750 \mathrm{MPa}$, a ratio of $750 / 120$. If the vertical stress is not a principal stress, then the two alternative minimum or maximum values will lie between the two maxima and minima values obtained.

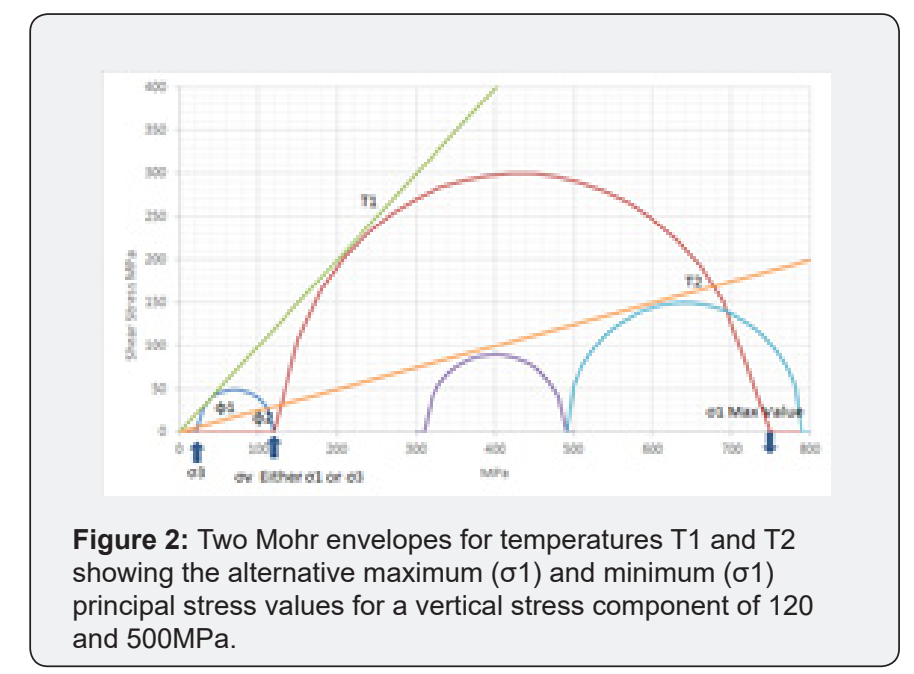

The vertical stress is one of the fundamental components of the methodology and is calculated using equation 5 (Table 1). The Mohr envelope is determined experimentally for different temperatures, Figure 3, and the resultant ratios either side of 
the vertical component is used to divide or multiply the vertical component to obtain either alternate principal stress. The next step in the methodology is to establish the ratios for a specific rock type. Figure 3 gives the strength data for basalt used to obtain an empirical relationship between the ratios for the different Mohr envelope inclination using equation 3. The third step in the methodology is to determine the relationship between vertical component and temperature. The temperature gradient varies significantly over the first $100 \mathrm{~km}$ below surface and for the present discussion equation 4 was used. It commences at $35^{\circ} \mathrm{C}$ at surface, reducing to $5^{\circ} \mathrm{C}$ at $300 \mathrm{~km}$ depth. For subduction zones thermal models developed by Syracuse et al. [2] are used.

Table 1: Equations used in the article with relevant constants for specific example.

Where $\sigma 1=$ Maximum principal stress; $\sigma 3=$ Minimum principal stress; $\sigma_{\mathrm{v}}=$ Vertical stress; $\Delta \mathrm{T}=$ Temperature gradient; $\rho=$ Density; $g$ = Gravity acceleration; $h$ = Depth below surface.figure3

\begin{tabular}{|c|c|c|c|c|c|}
\hline No & & Equation & Constant & Constant & \\
\hline 1 & Mohr circle radius & $\mathrm{r}=\left(\sigma_{1}-\sigma_{3}\right) / 2$ & & $\mathbf{R}^{2}$ \\
\hline 2 & Mohr circle centre & $\mathrm{d}=\left(\sigma_{1}+\sigma_{3}\right) / 2$ & & \\
\hline 3 & Mohr circle ratio & $\mathrm{R}=\mathrm{a}_{2} \operatorname{Exp}\left(\mathrm{b}_{2}{ }^{*} \mathrm{~T}\right)$ & -0.002 & 8.613 & 0.9432 \\
\hline 4 & Temperature gradient & $\Delta \mathrm{T}=\mathrm{a}_{1} \ln \sigma_{\mathrm{v}}+\mathrm{b}_{1}$ & -5.292 & 35.21 & 0.9953 \\
\hline 5 & Vertical stress & $\sigma_{\mathrm{v}}=\rho \mathrm{gh}$ & & & \\
\hline
\end{tabular}

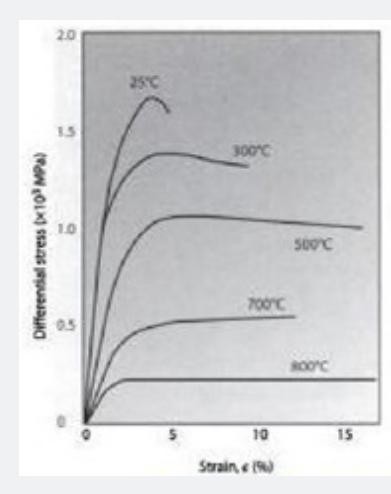

Figure 3: Strength of basalt for various temperatures with confinement stress of 550MPa.

\section{Verification Methods}

Results obtained using the proposed methodology need to be compared with existing observations for verification. For shallow processes, the existing and tested metamorphic facies diagrams are used to plot the pressure temperature values obtained with those on existing facies diagrams for basalt. For deeper regions such as the subduction zones, seismic data is the main source of information on the distribution, frequency, magnitude and stress drops are used for comparison with results obtained using the yield envelope concept.

\section{Base case model}

The yield envelope, Figure 4, is a typical gravitational scenario with the vertical component being a function of depth. The yield envelope is based on the fact that the vertical stress component is the maximum principal stress hence the yield envelope lies below the vertical stress value. For the minimum principal stress value lying within the envelope such as in a depositional basin the above is an example of a diagenetic loop. The induced horizontal stress component given as a function of the Poisson's ratio indicates a stable condition, diagenesis only. The central Karoo succession in South Africa is an example of this type of setting.

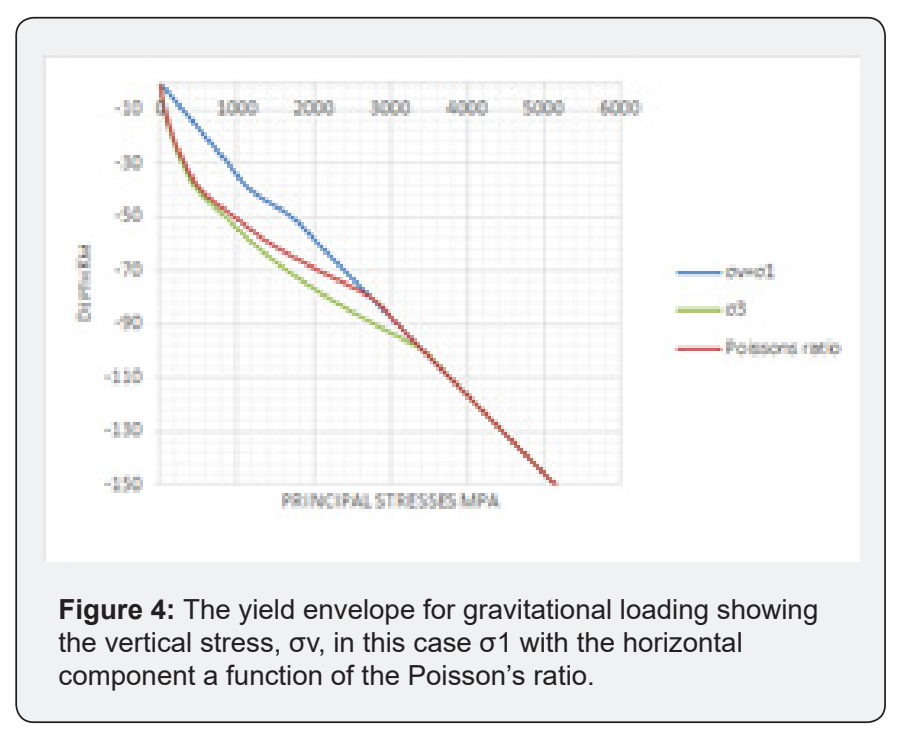




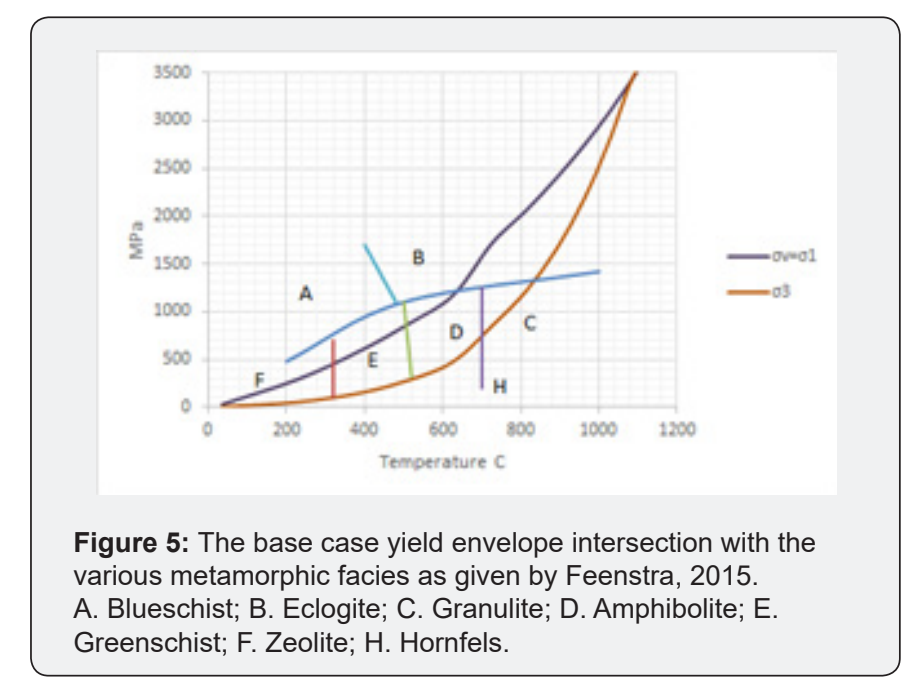

ncrease in the horizontal dimension due to uplift will reduce the induced horizontal stress. To a depth of $50 \mathrm{~km}$ the induced stress is very close to the yield envelope and a very small stress reduction is required to induce normal faulting. The minimum principal stress will retain its yield value even with further increase in the horizontal dimension, but there will be an increase in the number of normal faults. A good example of this type of event is the Central African Rift valley. The temperature/stress field is plotted on the metamorphic facies diagram for Basalt, Figure 5, ranging through the zeolite, greenschist, amphibolite, granulite to the Eclogite facies.

\section{High temperature gradients}

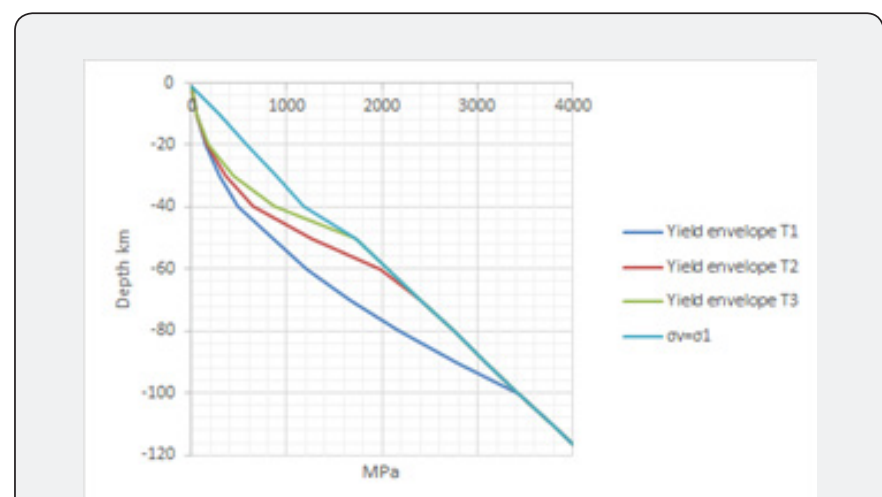

Figure 6: Yield envelopes for three temperature gradients for a gravitational induced stress condition.

An increase in the geothermal gradient, for instance such as the presence of a mantle plume, will have the effect of reducing the strength of the rock mass, reducing the stress values of the yield envelope, Figure 6 . The depth of the hydrostatic zone reduces from 100, 60 to $47 \mathrm{~km}$ depth. Figure 7 are the temperature stress envelopes for 3 temperature values. As the temperature gradient increases the metamorphic facies change to higher temperature regions for instance from the blueschist to the granulite facies for the deeper sections. The lower grades are less sensitive for instance the amphibolite and the greenschist stay in their respective fields, not very pressure sensitive. Contact metamorphic zones and regional increase in temperature in close proximity of massive intrusive bodies.

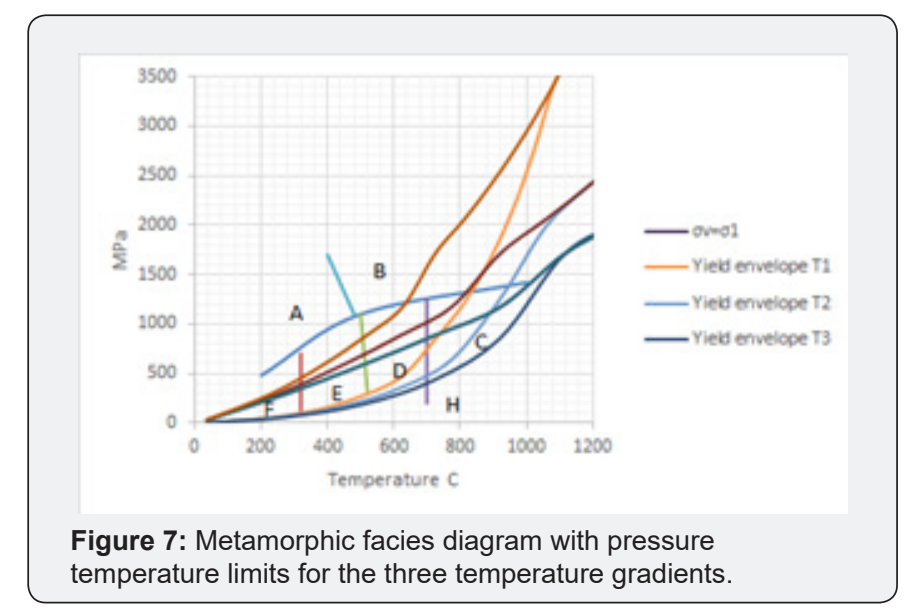

\section{Convergent zones}

The yield envelope for the base case where the horizontal stress is in excess of the vertical component is shown in Figure 8 using the same basic functional relationships discussed above. The hydrostatic zone is reached at about $100 \mathrm{~km}$ below surface apparently coincidental with the depth of the low velocity zone. All subduction zones must have been preceded by this scenario before the subduction commenced. The further deformation close to surface will be governed by the yield envelope in Figure 8. The metamorphic facies generally exposed on surface is correctly presented by the pressure-temperature plot obtained from the yield envelope. The Antigorite limit line is included to show that the general stress-temperature conditions in subduction zones lies outside the "normal" metamorphic stress-temperature changes. Examples of this scenario are abundant in the form of continental/continental collision or the earth crust in conjunction with subduction zones (Figure 9).

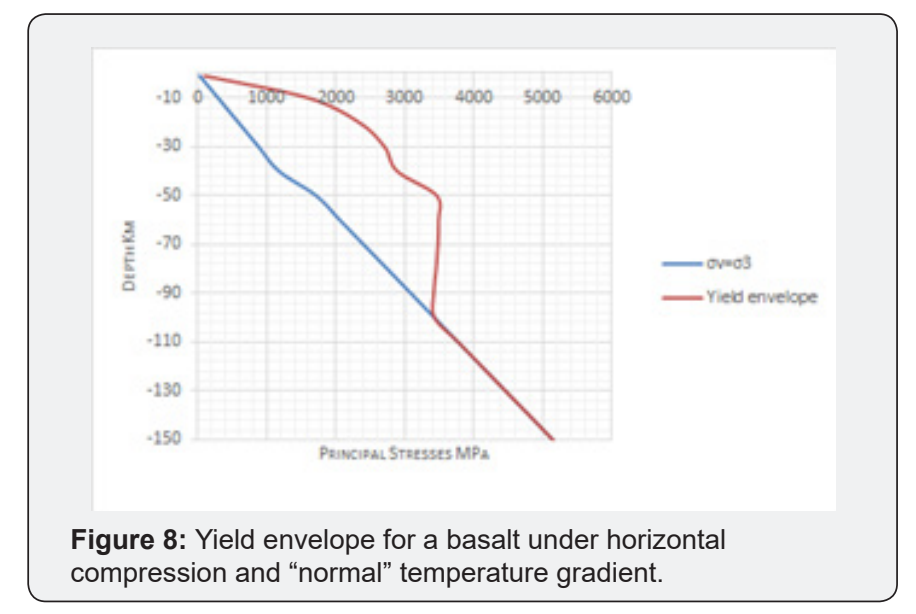




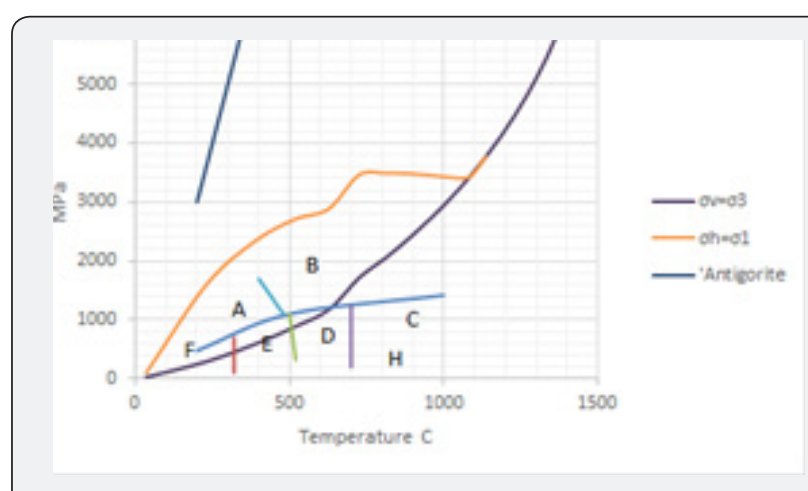

Figure 9: Metamorphic facies in a compressive stress field with the Antigorite limit included.

\section{Subduction zones}

Subduction zones discussed in the literature already exist and the reason for their commencement, initial break and progression in depth is still a matter of speculation. This article will, as the rest of the authors, for this publication accept an existing geometry which represents a snapshot of a dynamic system developing over $20 \mathrm{Ma}$ years or more. The dip of the subduction zones varies over a range of $20^{\circ}$ to $80^{\circ}$, with an average thickness of $150 \mathrm{~km}$ [2]. A knowledge of the temperature distribution in the subduction zone is one of the fundamental requirements and for the present discussion the thermal model, with its associated seismicity, published by van Keken et al. [3] is used as an example, Figure 10. For a subduction zone dipping at 450 the maximum principal stress within the zone is assumed to be parallel to the dip. The vertical component can therefore not be the maximum or minimum stress but is in the orientation of the maximum shear stress. For calculating the stress distribution in the subduction zone scenario, the maximum shear stress on the Mohr envelope defines the radius of the circle below the envelope. The centre intersection on the horizontal axis is given by the sum of the principal stresses divided by two. At the depth of $100 \mathrm{~km}$ or more, the assumption of an inclined Mohr envelope falls away and is defined by a straight line parallel to the principal stress axis and the radius of the Mohr circle defined by equation 6.

$$
\text { ô }=\mathrm{a} 8 \mathrm{ó}_{\mathrm{v}}+\mathrm{a} 9(6)
$$

Where $\tau=$ Shear stress; $a_{8}=-.9727 ; a_{9}=937 ; \sigma_{v}=\left(\sigma_{1}-\sigma_{3}\right) / 2 ; R=$ 0.9525

The constant $\mathrm{a}_{9}$ is the smelting point of the basalt in the example. Equation 6 replaces equation 1 in the spreadsheet for calculating the yield envelope for a 450-dip subduction zone. In the case of the subduction zone discussion, the yield envelope becomes a strength envelope of the subducted slab. The core being "strong" with reduction towards the top and bottom. The yielding envelope of the host rock is given by a point on the Mohr diagram, a stronger medium penetrating into the hydrostatic zone will be similar to an object falling into an ocean trench; it will be subjected to immense hydrostatic stress but not be restrained by shear strength, this being close to zero in the example. Figure 11 shows the strength envelopes for four sections through a subduction zone at 80,120 , 180 and $220 \mathrm{~km}$ below surface. The temperatures were obtained from the thermal model, [3] Figure 10, which for the present discussion compares well with those published by Syracuse et al. [2]. Figure 12 shows the shear stress variation across the zone as well as with depth. The reduction in shear strength is due to the decrease in width of the low temperature core of the sub-ducted material.

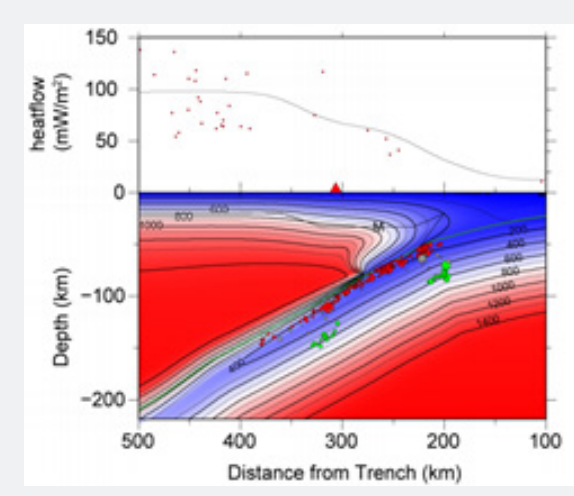

Figure10: Thermal model and general geometry of subduction zone beneath Japan, from [3].

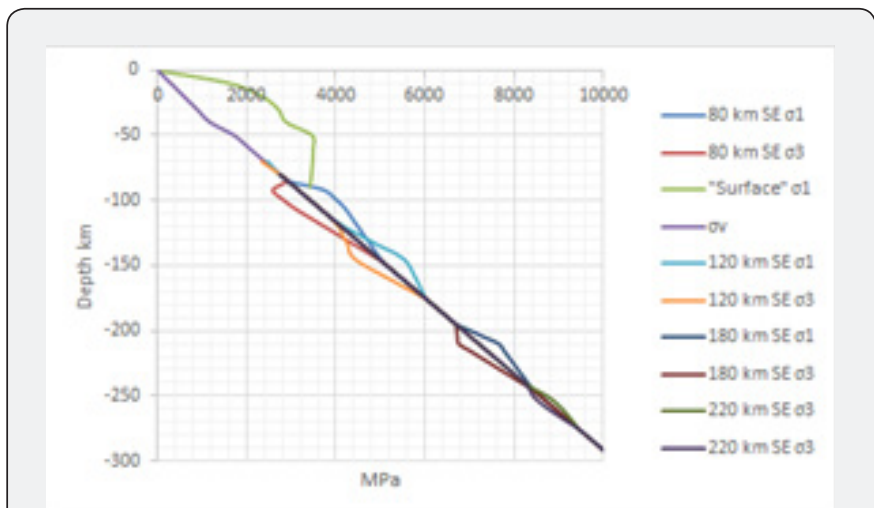

Figure11: Strength envelopes for sections from surface to $100 \mathrm{~km}$ depth and four elevations through the subduction zone.

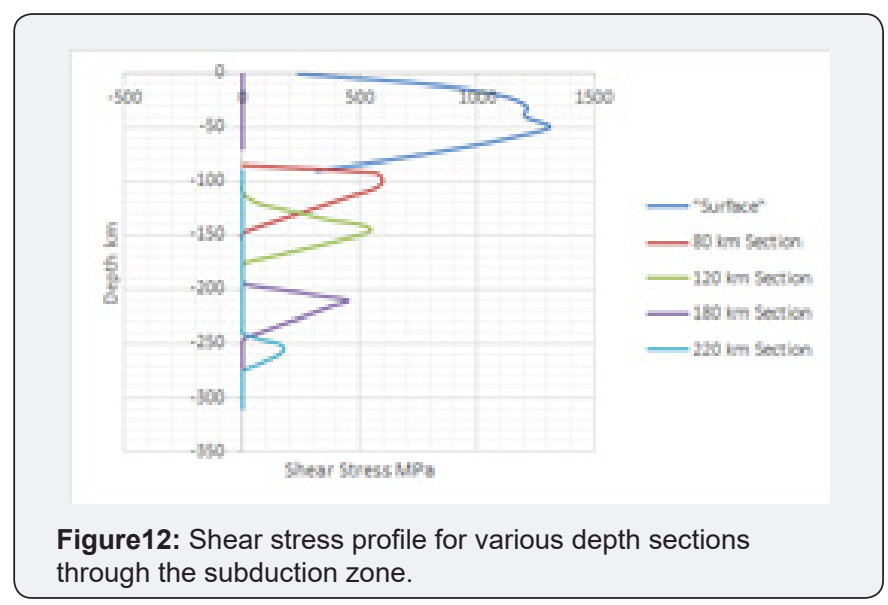


The pressure-temperature plot for the subduction zone at various depths falls well outside the accepted metamorphic facies diagram and seismic data is the main source for comparative studies. Min Chen et al. [4] defines the seismic zones in pressuretemperature diagrams and the spread of the seismic activity falls well within the limits obtained by using the strength envelope. The picture for the subduction zone that emerges has the following attributes:

i. The yield envelope for the first $100 \mathrm{~km}$ is defined by the functional relationship given by equations 3, 4 and 5 . Depth in excess of $100 \mathrm{~km}$, equation 6 is used for the inclined portion.

ii. In the case of a subduction zone the yield envelope should rather be called the strength envelope since the solid core of the slab is the governing component.

iii. For the current model the hydrostatic stress, smelting point of basalt, is reached at $9370 \mathrm{C}$.

iv. Based on the thermal model the subduction zone has a non-hydrostatic inner core limited by the tapering 9370C contour.

v. The stress gradient is higher near the top of the slab than at the bottom, becoming symmetrical below $180 \mathrm{~km}$.

vi. By extrapolation the shear stress in the slab reaches zero, or hydrostatic condition, at a depth of $300 \mathrm{~km}$.

vii. Brittle failure, or a slight negative slope of the stress strain curve, is most likely in the temperature region between 900 and 7500C.

viii. The pressure-temperature plot of metamorphic facies, Figure 13, shows that the values in the subduction zone are not catered for by those generally described in the literature.

ix. It is anticipated that with increase in the width of the subduction zone, the "core" will extend to greater depths.

A vast amount of seismic data is available and is the main source of information about the mechanism of events at great depth. The data selected for comparative/analytical analysis are contained in articles by Shawn Wei et al., Min Chen et al., Van Keken PE \& Allmann BP [3-6]. The main findings for the benefit of the current exercise are:

i. Frequency of seismic events is highest in the top of the slab to a depth of $100 \mathrm{~km}$. Symmetric distribution is reached at approximately 100 to $160 \mathrm{~km}$ and terminates at $160 \mathrm{~km}$. This is corroborated by the steep strength gradient predicted by the strength envelope.

ii. A double seismic zone occurs from 80 to $130 \mathrm{~km}$ due to the fact that the core of the subduction zone does not fail under reigning stress differentials.

iii. The width of the seismic zone reduces with depth in some instances. iv. Plots of seismic events on pressure-temperature diagrams by Shawn Wei et al. [5] are relatively insensitive to pressure and limited to a temperature range between $20^{\circ}$ and $1100^{\circ} \mathrm{C}$.

v. The stress drop in subduction seismic zones is on average less than $5 \mathrm{MPa}$ which supports the finding above that small differential stresses are the main cause of the displacement on the edges of the subduction zone.

The findings of the proposed methodology in conjunction with thermal models correlates well with seismic observations. For additional elucidation, Figure 14 is a repeat plot of Figure 12 with the addition of a differential stress of 450MPa equivalent to a temperature contour of $750^{\circ} \mathrm{C}$. The conclusions that can be drawn from the diagram are:

i. The frequency of seismic reduces with depth; maximum close to surface reducing to zero at a depth of $200 \mathrm{~km}$, borne out by Figures $11 \& 12$.

ii. The frequency is generally higher on the top of the slab.

iii. Double seismic zones occur over a depth range of 80 to $130 \mathrm{~km}$, supported by Figure 14.

iv. Seismicity reduces to zero at a depth of $300 \mathrm{~km}$, Figure 11.

v. The seismic distribution limits on the pressuretemperature coincide with those of the strength envelopes, Figure 13.

The correlation with actual seismic data is convincing enough to conclude that the proposed methodology has potential for calculating the yield limits, hence the acting stress field, at depths of $500 \mathrm{~km}$ [7].

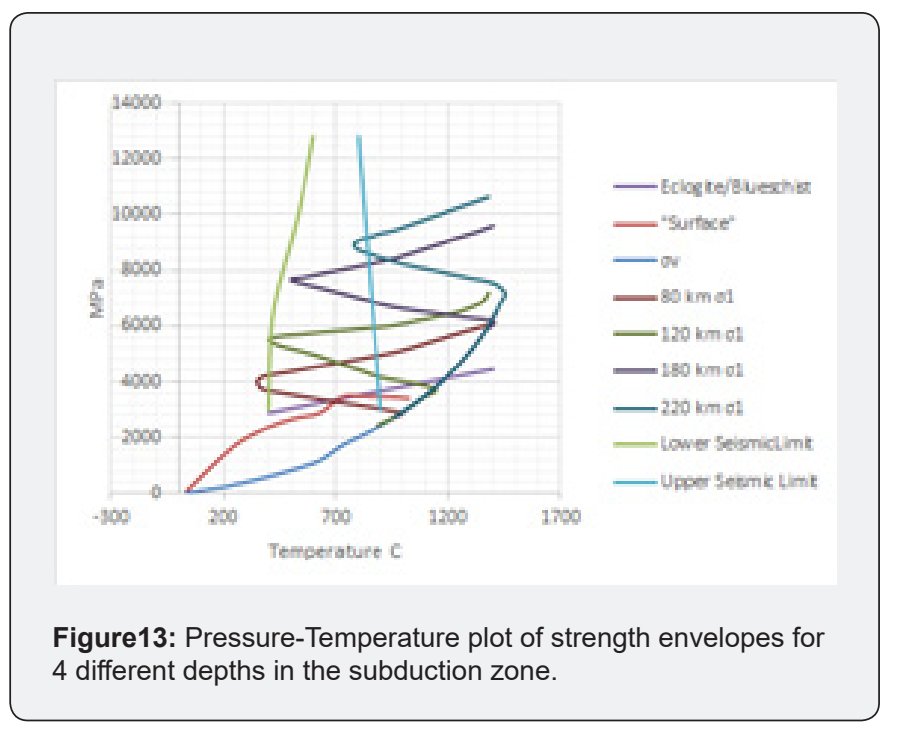




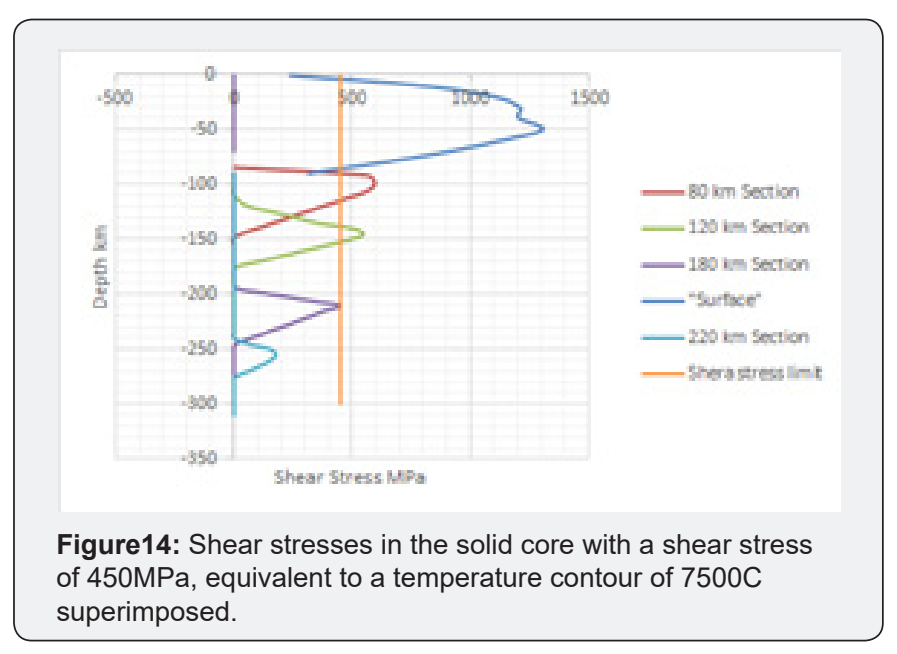

\section{Discussion and Conclusion}

The proposed methodology to determine the geo-tectonic yield envelope is based on the concept of the Mohr envelope, the knowledge of the vertical stress and the temperature model. Using these concepts, it is possible to determine the maximum and minimum principal stresses in the earth lithosphere and astenosphere. Experimental values for the strength of basalt are used to establish the functional relationships between stresses and temperature where it was found that the observations with regard to metamorphic zones and occurrence of seismicity in space can be explained by applying the concept of a yield envelope. It is by no means implied that the assumed values of the strength of basalt and the functional relationships are the ultimate answer, rather, they are initial empirical estimates and can probably be improved significantly for specific rock types and regions. The driving forces pose an additional challenge. The rate of subduction and the rate of rheological flow beneath the slab will play a major role in the seismic activity. The deformation is at a maximum between the "roof" and the slab. With a rate of displacement of $50 \mathrm{~km} / \mathrm{Ma}$ of the slab the rate of the driving mechanism, or the "conveyer belt", must be the same or more. If the rates are the same, the seismic signature for the top and bottom of the slab should be the same but for a rate differential the seismic signature must reverse as discussed by Shawn Wei et al. [5].

The above discussion describes a "snapshot" of subduction zones as they are at present and exhuming one of these features seems highly unlikely leaving many questions unanswered. A point in fact is the "volume balance of subduction". A $150 \mathrm{~km}$ thick slab is subducted at an angle of $45^{\circ}$ the surface above it should be lifted by $150 \mathrm{~km}$. In addition, according to Syracuse et al. [2] data the average oceanic subduction zone is age 80Ma years and with an average subduction rate of $50 \mathrm{~km} \mathrm{Ma}$, the total "distance" is $4000 \mathrm{~km}$. Seismicity seems to be able to delineate the zone to depths of 400 to $600 \mathrm{~km}$, but what happens thereafter is open for discussion.

\section{References}

1. Kersten RWO (2019) An Alternative Pillar Design Methodology. Journal of South African Institute of Mining and Metallurgy. 119: 471-478.

2. Syracuse M, Van Keken PE, Abers A (2010) The Global Range of Subduction Zone Thermal Models. Physics of the Earth and Planetary Interiors 183(1-2): 73-90.

3. Van Keken PE, Kita S, Nakajima J (2012) Thermal Structure and Intermediate-Depth Seismicity in the Tokohu-Hokkaido Subduction Zones. Solid Earth 3: 355-364.

4. Chen M, Manea VC, Niu F, Wei SS, Kiser E (2019) Genesis of IntermediateDepth and Deep Intraslab Earthquakes Beneath Japan Constrained by Seismic Tomography, Seismicity and Thermal Modelling. American Geophysical Union 46(4): 2025-2036.

5. Shawn Wei S, Wiens DA, Van Keken PE, Chen Chai (2017) Slab Temperature Controls on the Tonga Double Seismic Zone and Slab Mantle Dehydration. Science Advances 3(1): 1-9.

6. Allmann BP, Shearer PM (2009) Global variation of shear Stress drops for Moderate to Large Earthquakes. Journal Geophysical Research 114 (B01310): 1-22.

7. Feenstra GF (2015) Regional Metamorphism. Environmental Sciences.

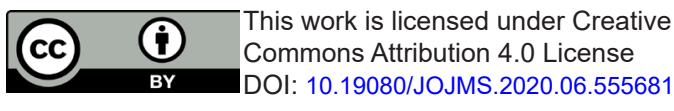

\begin{tabular}{l} 
Your next submission with JuniperPublishers \\
will reach you the below assets \\
- Quality Editorial service \\
- Swift Peer Review \\
- Reprints availability \\
- E-prints Service \\
- Manuscript Podcast for convenient understanding \\
- Global attainment for your research \\
- Manuscript accessibility in different formats \\
( Pdf, E-pub, Full Text, Audio) \\
- Unceasing customer service \\
Track the below URL for one-step submission \\
https://juniperpublishers.com/submit-manuscript.php \\
\hline
\end{tabular}

